Article

\title{
Computer-Assisted Preoperative Simulations and 3D Printed Surgical Guides Enable Safe and Less-Invasive Mandibular Segmental Resection: Tailor-Made Mandibular Resection
}

\author{
Bo-Yeon Hwang ${ }^{1, \dagger}$, Jae-Yeol Lee ${ }^{2,+}$, Junho Jung ${ }^{1}$, Joo-Young Ohe ${ }^{1}$, Young-Gyu Eun ${ }^{3}{ }^{\mathbb{D}}$, \\ YoungChan Lee ${ }^{3}$ and Jung-Woo Lee ${ }^{1, *(D)}$ \\ 1 Department of Oral and Maxillofacial Surgery, School of Dentistry, Kyung Hee University, \\ Seoul 02447, Korea; bo0426@hanmail.net (B.-Y.H.); ssa204@khu.ac.kr (J.J.); ojyoung81@khu.ac.kr (J.-Y.O.) \\ 2 Department of Oral and Maxillofacial Surgery, Dental and Life Science Institute, Dental Research Institute, \\ School of Dentistry, Pusan National University, Yangsan 46241, Korea; omsljy@pusan.ac.kr \\ 3 Department of Otolaryngology—Head and Neck Surgery, School of Medicine, Kyung Hee University, Seoul \\ 02447, Korea; ygeun@khu.ac.kr (Y.-G.E.); medchan@hanmail.net (Y.L.) \\ * Correspondence: omsace@khu.ac.kr; Tel./Fax: +82-2-9589-9440 \\ + Bo-Yeon Hwang and Jae-Yeol Lee contributed equally as the first authors to this work.
}

Received: 31 January 2020; Accepted: 13 February 2020; Published: 15 February 2020

\begin{abstract}
This study aimed to present and evaluate alternative lesion-specific mandibulectomy methods for preserving the mandibular anatomical structures as compared with the conventional virtual surgical plan. Fifteen patients who received segmental mandibulectomy were included in this study, and the following parameters were evaluated: (1) the disease-free bone margin, (2) the volume and surface between the tailor-made resection simulation and conventional resection simulation, and (3) the preserved mandibular anatomical structures. In all 15 patients, disease-free bone margins were confirmed by histopathology. Volumes of conventional resection simulation and tail-made resection simulation were 49,468.66 $\pm 14,007.96 \mathrm{~mm}^{3}$ and 52,610.01 $\pm 13,755.33 \mathrm{~mm}^{3}$ and the surfaces were 20,927.38 $\pm 4471.70 \mathrm{~mm}^{2}$ and 22,356.49 $\pm 4185.73 \mathrm{~mm}^{2}$, respectively; these were statistically significant (both, $p<0.001$ ). Mandibular dentition was partially preserved in six patients. Twelve of the 15 patients had changes in defect classification with preservation of the mandibular inferior border. In conclusion, alternative lesion-specific mandibulectomy was a less invasive method for effectively removing mandibular lesions while preserving the important anatomical structures of the mandible.
\end{abstract}

Keywords: computer-assisted surgery (CAS); segmental mandibulectomy; computer-aided design/ computer-aided manufacturing (CAD/CAM); preoperative-surgical simulation; less-invasive surgery

\section{Introduction}

In diseases of the oral cavity, such as malignant or benign tumors, extensive trauma, osteoradionecrosis, osteomyelitis, or medication-related osteonecrosis of the jaw, segmental mandibulectomy is often inevitable. Segmental mandibulectomy results in a mandibular continuity defect which often leads to serious functional and aesthetic complications, therefore, adequate reconstruction of mandibular defects is essential [1-3]. Since accurate mandibulectomy and appropriate reconstruction are challenging issues, recently, computer-assisted surgery (CAS) has been introduced and widely used in clinical practice. This technique includes preoperative virtual surgical planning (VSP) based on a patient's images, such as computed tomography (CT) and magnetic resonance 
imaging (MRI), and preparation of surgical guides by computer-aided design and computer-aided manufacturing (CAD/CAM) technologies and adding materials layer by layer to transfer VSP into the operative field. These three-dimensional (3D) printed surgical guides are used for the resection of the mandible, and to shape the free bone flap [4-6]. The advantages of CAS are reduction of the operative time and aesthetic and functional results through anatomical reconstructions $[7,8]$. Additionally, it has been reported that CAS can more safely and accurately resect the mandibular malignancies with VSP performed using various imaging modalities, such as CT and MRI simultaneously [9].

Despite a large number of advantages and various osteotomy lines that can be designed, most of the literature on CAS has shown designs of straight mandibular resection lines. Straight mandibular resection lines make the overall surgical procedure easier but more mandibular anatomical structures could be resected even if they are not affected by the disease. These unnecessarily resected anatomical structures are mostly predicted to be the lower teeth, the mandibular inferior borders, and these structures are important for function and aesthetics.

Therefore, the purpose of this study was to present and evaluate alternative lesion-specific mandibulectomy (tailor-made mandibular resection) methods for preserving the mandibular anatomical structures as compared with the previous virtual surgical plan.

\section{Materials and Methods}

\subsection{Patients and Inclusion Criteria}

This retrospective study included patients who underwent mandibular segmental resection at the Department of Oral and Maxillofacial Surgery of Kyung Hee University Dental Hospital between December 2016 and November 2017. The indications for mandibular resection included osteoradionecrosis, and nonmalignant and malignant tumors. The study included only patients who had undergone both preoperative CT and MRI and postoperative CT of the craniofacial region. Before starting this study design, ethical approval was received from the institutional review board (approval number KHD IRB 1806-2). Written informed consent was obtained from all patients in the study. Preoperative surgical simulations, designs of surgical guides, and operations were all performed by a single experienced surgeon under confirmation of head and neck radiologists.

\subsection{Data Acquisition and Three-Dimensional Virtual Models Preparation for Preoperative Surgical Simulation}

Before surgical simulation, the patient's craniofacial region was initially scanned using both CT and MRI. The CT scans of the craniofacial region were taken with the patient in the supine position at a slice thickness of $1 \mathrm{~mm}$ (Brilliance CT 64-channel scanner, Philips Healthcare, Best, Netherlands). The protocol of MRI consisted of T1-weighted and T2-weighted sequences, T1 fat-suppressed sequences, T2 fat-suppressed sequences, and diffusion-weighted sequences after intravenous administration of a contrast agent (Philips Achieva 3.0T TX, Philips Healthcare). Additionally, a positron emission tomography (PET)-CT was performed for the staging of malignant tumors.

Image datasets were imported as Digital Imaging and Communications in Medicine (DICOM) files into Mimics 20.0 software (Materialise, Leuven, Belgium). The DICOM datasets of CT and MRI were segmented as the cranio-maxilla region and mandible. In the case of osteoradionecrosis, the lesion areas were segmented using CT images, and the tumors were segmented on MRI. Segmented cranio-maxilla regions, mandibles, and lesions were reconstructed into three-dimensional (3D) virtual models. With an additional medical software program (3-Matic 12.0, Materialise), the 3D reconstructed $\mathrm{CT}$ and MRI mandible models were superimposed images. As a result, tumors segmented in MRI were fused on the mandibular 3D virtual model converted from CT. Finally, the segmented tumors were uniformly increased to $10 \mathrm{~mm}$ for a safety margin, and the virtual model for preoperative surgical simulation was completed (Figure $1 \mathrm{~A}-\mathrm{C}$ ). 

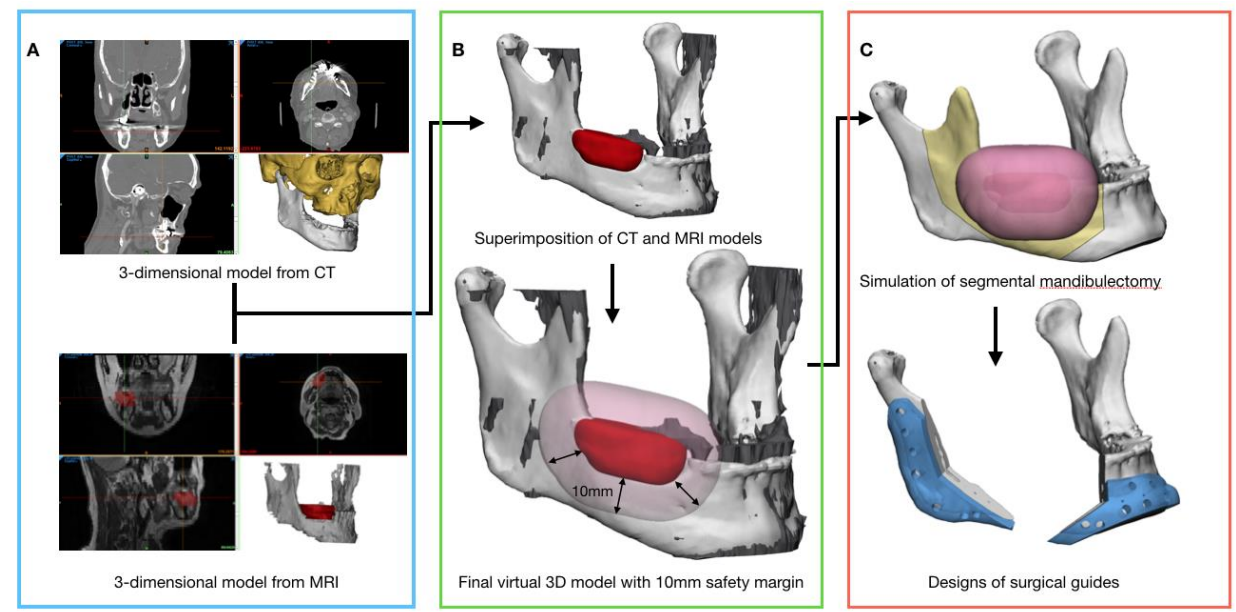

Figure 1. Digital workflow of preoperative surgical simulation and guide fabrication. (A) A threedimensional cranio-maxilla and mandible model is generated from computed tomography (CT) and a three-dimensional mandible with a localized tumor from magnetic resonance imaging (MRI) is generated by the medical software; (B) by superimposing three-dimensional models of CT and MRI, tumor information obtained from MRI is shared with the high-resolution mandibular bone model from CT; (C) preoperative surgical simulation of the final virtual three-dimensional model and design of the surgical guides transferred from virtual reality to the operating room.

\subsection{Preoperative Surgical Simulation and Fabrication of the Surgical Guides}

Resection planning was performed in two ways according to the principles of osteoradionecrosis and radical tumor resection. The first method was conventional mandibular resection with straight-line osteotomies, and the second was tailor-made resection, which was performed in various shapes of osteotomies depending on the type of lesion, as shown in Figure 2A-E. During the operation, results of the tailor-made resection simulation were used. In order to transfer the results of surgical simulation to the surgical field, surgical guides for mandibular resection were designed using a medical CAD software (3-Matic 12.0, Materialise), and fabricated using a 3D printer in every case. Finally, the surgical guides were delivered for sterilization (Figure 2A-D).
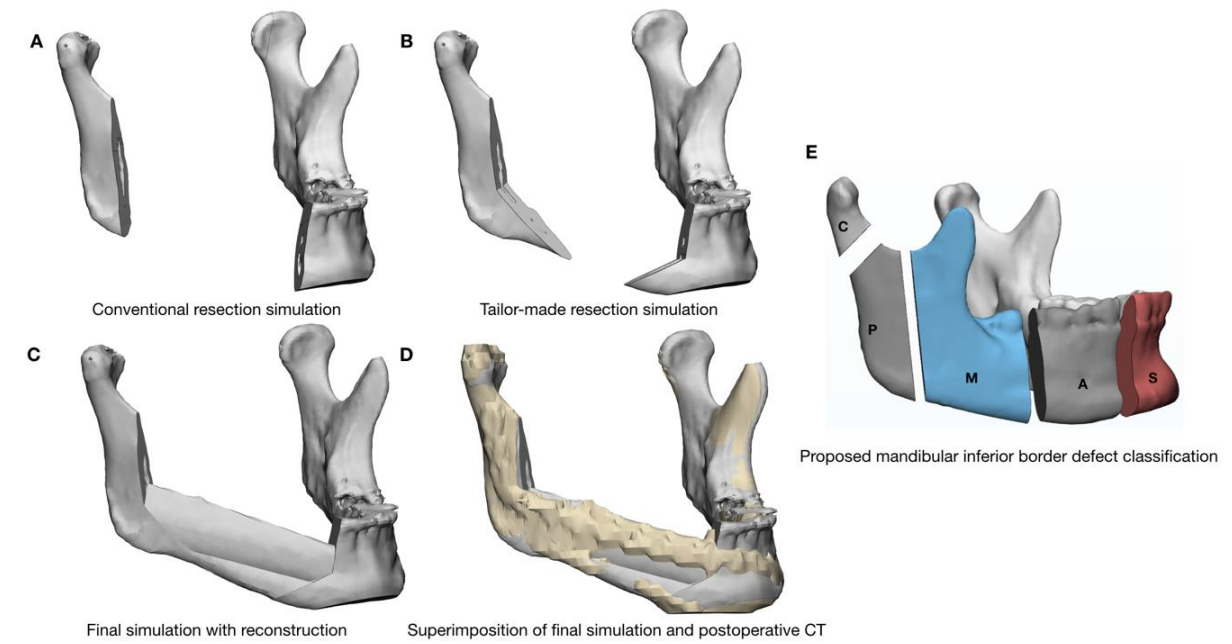

Figure 2. Evaluation methods of surgical outcomes. (A) The volume and surface of conventional resection and (B) tailor-made resection simulation are automatically calculated using medical computer-aided design software; (C) final simulation with reconstruction is compared to (D) postoperative computed tomography (CT). Then, (D) is compared to (A) to evaluate preservation of the mandibular anatomy structures; (E) Proposed new mandibular border defect classification. 


\subsection{Evaluation Methods of the Surgical Outcomes}

To evaluate the clinical safety of tailor-made mandibular resection, the bone margin was assessed through histopathology reports. Moreover, disease recurrence, metastasis, and survival of patients, during the follow-up period, were evaluated.

Comparisons were made between the conventional resection simulation and the tailor-made resection simulation after superimposition of the postoperative 3D model obtained from a CT scan taken two to four weeks postoperatively. Using the overlapped images, the anatomical structures preserved after actual surgery were investigated. In addition, the volume and surface of the preserved mandible after resection were automatically calculated and compared with the two simulation methods using medical CAD software (3-Matic 12.0, Materialise).

A new defect classification was introduced to evaluate the inferior border of the mandible in this study. This classification method classified the inferior border of the mandible as symphysis $(\mathrm{S})$, the anterior mandibular body $(\mathrm{A})$, middle mandibular body $(\mathrm{M})$, posterior mandibular body $(\mathrm{P})$, and condyle $(\mathrm{C})$ according to the range of resection of the inferior border of mandibular, which is aesthetically and functionally important. We called this classification method "SAMPC" classification (Figure 2E). By using this classification, we compared the preservation of the mandibular inferior border with the tailor-made resection simulation and the conventional resection simulation.

\subsection{Statistical Analysis}

R Statistical Package ( $\mathrm{R}$ for Mac, release 3.6.1, 2019; R Foundation for Statistical Computing, Vienna, Austria) was used to perform statistical analysis, and Prism 8.0 (Graph Pad Software, La Jolla, CA, USA) was used to generate graphs. Descriptive statistics were applied for all variables, which were expressed as a mean and standard deviation. The normality of the variables was tested by using the Kolmogorov-Smirnov test. Paired $t$-tests were used to calculate differences of the volume and surface between conventional resection simulation and the tailor-made resection simulation, $p$-values less than 0.05 were considered statistically significant.

\section{Results}

Eighteen patients underwent segmental mandibular resection between December 2015 and November 2017. Three patients were excluded because of a lack of MRI data. Fifteen patients who fulfilled the inclusion criteria consisted of 10 men and five women with a mean age of 60 years (range 31-79 years). Thirteen patients presented with a primary tumor (three patients with ameloblastoma, nine patients with squamous cell carcinoma, and one patient with osteosarcoma), and two patients presented with osteoradionecrosis of the mandible (Table 1). The median follow-up was 28 months (Table 2).

Both the surgical guides and prebent plates fit well on the mandible in all cases. No patient needed modification of the preoperative surgical planning of mandibular resection intraoperatively. The operations of all cases were uneventful, and no complications were observed during surgery or the follow-up period (Table 2).

In all 15 patients, disease-free bone margins were confirmed by histopathology. However, in one patient, a positive margin was identified in the soft tissue that was very close to the skull base. Fourteen patients included in this study survived without recurrence. One patient had a distant metastasis in the lung during the follow-up and died (Patient 11).

Volumes of conventional resection simulation and tailor-made resection simulation were 49,468.66 $\pm 14,007.96 \mathrm{~mm}^{3}$ and $52,610.01 \pm 13,755.33 \mathrm{~mm}^{3}$, and surfaces were $20,927.38 \pm 4471.70 \mathrm{~mm}^{2}$ and $22,356.49 \pm 4185.73 \mathrm{~mm}^{2}$, respectively. Between the two kinds of simulations, both volume and surface were statistically significant $(p<0.001)$ (Table 3$)$. Mandibular dentition was partially preserved in six patients, and canines were preserved in five patients. Twelve of 15 patients showed changes in the defect classification with preservation of the mandibular inferior border (Table 2). 
Table 1. Patient demographic and clinical data.

\begin{tabular}{cccccc}
\hline \multirow{2}{*}{ Patient No. } & Sex & Age (Years) & Diagnosis & \multicolumn{2}{c}{ Method of Reconstruction } \\
\cline { 4 - 5 } & & & & Microvascular Free Flap & Fixation Method \\
\hline & M & 37 & Ameloblastoma & FFF & Miniplates \\
3 & F & 52 & SCC & FFF & Miniplates \\
4 & F & 56 & ORN & FFF & R-plate \\
5 & M & 63 & ORN & FFF & Miniplates \\
6 & F & 44 & Ameloblastoma & DCIA & R-plate \\
7 & M & 56 & SCC & FFF & Miniplates \\
8 & M & 62 & SCC & FFF & Riniplates \\
9 & M & 78 & Osteosarcomate & R-plate \\
10 & M & 31 & Ameloblastoma & FFF & R-plate \\
11 & M & 79 & SCC & FFF & R-plate \\
12 & F & 74 & SCC & FFF & Miniplates \\
13 & F & 75 & SCC & FFF & R-plate \\
14 & M & 60 & SCC & FFF & R-plate \\
15 & M & 70 & SCC & FFF & \\
\hline Total & M & 65 & SCC & & \\
n & men & Mean (SD) & & & \\
\hline
\end{tabular}

Abbreviations: F, female; M, male; ORN, osteoradionecrosis; SCC, squamous cell carcinoma; FFF, fibula free flap; DCIA, deep circumflex iliac artery bone flap; R-plate, reconstruction plate; SD, standard deviation; no., number. 
Table 2. Clinical patients' outcomes.

\begin{tabular}{|c|c|c|c|c|c|c|c|c|}
\hline \multirow[t]{2}{*}{ Patient No. } & \multirow{2}{*}{$\begin{array}{c}\text { Conventional } \\
\text { Resection Simulation }\end{array}$} & \multirow{2}{*}{$\begin{array}{l}\text { Tailor-Made Resection } \\
\text { Simulation }\end{array}$} & \multirow{2}{*}{$\begin{array}{l}\text { Tailor-Made Resection } \\
\text { Simulation Vs. Post-OP }\end{array}$} & \multirow{2}{*}{$\begin{array}{l}\text { No. of Teeth } \\
\text { Saved }\end{array}$} & \multicolumn{2}{|c|}{$\begin{array}{l}\text { Mandibular Border } \\
\text { Defect Classification }\end{array}$} & \multirow{2}{*}{$\begin{array}{l}\text { Disease-Free } \\
\text { Bone Margins }\end{array}$} & \multirow{2}{*}{$\begin{array}{l}\text { Recurrence/Metastasis } \\
\text { (Follow-Up Period, Months }\end{array}$} \\
\hline & & & & & Primary & Final & & \\
\hline 1 & & & & $\begin{array}{c}1 \\
(\# 33)\end{array}$ & SAM & $\mathrm{AM}$ & yes & no (34) \\
\hline 2 & & & & 0 & SA & A & yes & no (35) \\
\hline 3 & & & & $\begin{array}{c}3 \\
(\# 41,42,43)\end{array}$ & MAS & MA & yes & no (17) \\
\hline 4 & & & & 0 & MASS & MA & yes & no (23) \\
\hline 5 & & & & $\begin{array}{c}1 \\
(\# 43)\end{array}$ & MAS & $\begin{array}{l}\text { Preservation of the whole } \\
\text { mandibular border }\end{array}$ & yes & no (29) \\
\hline 6 & & & & 0 & MA & MA & yes & no (31) \\
\hline 7 & & $y$ & & 0 & $\mathrm{AM}$ & $\mathrm{AM}$ & yes & no (25) \\
\hline 8 & & & & 0 & MPC & PC & yes & no (29) \\
\hline 9 & & & & $\begin{array}{c}1 \\
(\# 35)\end{array}$ & $\mathrm{AM}$ & $\mathrm{AM}$ & yes & no (35) \\
\hline 10 & & $y$ & & $\begin{array}{c}1 \\
(\# 33)\end{array}$ & SAM & $\mathrm{AM}$ & yes & no (29) \\
\hline 11 & $y$ & & & 0 & CPMAS & $\mathrm{CP}$ & $\begin{array}{l}\text { Yes (soft tissue } \\
\text { involvement) }\end{array}$ & distant metastasis, lung (16) \\
\hline
\end{tabular}


Table 2. Cont

\begin{tabular}{|c|c|c|c|c|c|c|c|c|}
\hline \multirow{2}{*}{ Patient No. } & \multirow{2}{*}{$\begin{array}{c}\text { Conventional } \\
\text { Resection Simulation }\end{array}$} & \multirow{2}{*}{$\begin{array}{l}\text { Tailor-Made Resection } \\
\text { Simulation }\end{array}$} & \multirow{2}{*}{$\begin{array}{l}\text { Tailor-Made Resection } \\
\text { Simulation Vs. Post-OP }\end{array}$} & \multirow{2}{*}{$\begin{array}{l}\text { No. of Teeth } \\
\text { Saved }\end{array}$} & \multicolumn{2}{|c|}{$\begin{array}{l}\text { Mandibular Border } \\
\text { Defect Classification }\end{array}$} & \multirow{2}{*}{$\begin{array}{l}\text { Disease-Free } \\
\text { Bone Margins }\end{array}$} & \multirow{2}{*}{$\begin{array}{c}\text { Recurrence/Metastasis } \\
\text { (Follow-Up Period, Months) }\end{array}$} \\
\hline & & & & & Primary & Final & & \\
\hline 12 & $y$ & & & 0 & MASS & $\begin{array}{l}\text { Preservation of the } \\
\text { mandibular border }\end{array}$ & yes & no (23) \\
\hline 13 & & & & 0 & MA & A & yes & no (27) \\
\hline 14 & E & & & 0 & MA & A & yes & no (29) \\
\hline 15 & $y$ & 9 & & $\begin{array}{c}1 \\
(\# 33)\end{array}$ & SAM & $\mathrm{AM}$ & yes & no (21) \\
\hline
\end{tabular}

Abbreviations: C, condyle; P, posterior mandibular body; M, middle mandibular body; A, anterior mandibular body; S, symphysis; no., number. 
Table 3. Comparison of the volumes and surfaces between conventional resection simulation and tailor-made resection simulation.

\begin{tabular}{ccccc}
\hline & $\begin{array}{c}\text { Conventional } \\
\text { Resection }\end{array}$ & $\begin{array}{c}\text { Tailor-made } \\
\text { Resection }\end{array}$ & Difference & $p$-Value \\
\hline Mean (SD) & Mean (SD) & Mean (SD) & \\
\hline Volume $\left(\mathbf{m m}^{\mathbf{3}}\right)$ & $49,468.66(14007.96)$ & $52,610.01(13755.33)$ & $-3141.35(1355.14)$ & $<0.001$ \\
Surface $\left(\mathbf{m m}^{\mathbf{2}}\right)$ & $20,927.38(4471.70)$ & $22,356.49(4185.73)$ & $-1419.10(554.67)$ & $<0.001$ \\
\hline
\end{tabular}

Abbreviation: SD, standard deviation.

\section{Discussion}

This study showed that tailor-made mandibular resection, carefully planned three-dimensionally using multimodal image information, is a safe and less invasive method than conventional resection. Although malignant tumors were included in this study, all patients showed a disease-free bone resection margin in histopathology, and none showed local recurrence. In the case of malignant lesions, the combined use of CT and MRI information helped us to accurately determine the location and size of the lesions. Many studies have suggested that using multimodal imaging (CT, cone-beam CT, MRI, (18)F-fluoro-2-deoxy-D-glucose PET, and PET/CT) together could improve accuracy of the diagnosis of bone invasion [10-13]. Particularly in radiation oncology, obtaining information from various images contributed to the successful results of radiotherapy [14]. Diagnosis and treatment based on various images have been also applied to a craniomaxillofacial surgical field with the development of CAS based on 3D images. The clinical application of this method not only diagnoses bone invasion but it also aids in surgery, as the size, location of diseases, and relationship of surrounding tissues are directly visualized in three dimensions $[9,15]$. In our study, all simulation procedures including determination of surgical margins were performed by an operator under confirmation of head and neck radiologists. This was possible because CAS was effective to communicate the disease-extension and surgical margin with the radiologist through the three-dimensional image. Our study showed good results similar to those in a previous study [9]. One patient died of distant metastasis, but in this case, there was a positive margin in the soft tissue of the non-resectable area (near the skull base), but the bone margin was disease-free in histopathology.

In our study, 3D lesions were extracted from MRI images and superimposed on 3D CT images for surgical simulation. Additionally, in the case of tumors, the 3D tumors were uniformly increased to $10 \mathrm{~mm}$. This procedure made it easy to set the safety margins of the disease and to design various types of osteotomies. Many studies have emphasized the advantages of using CAS to save time, ensure accurate results, and obtain aesthetic results, but no study has investigated the benefits of preserving anatomical structures using various types of osteotomies $[2,4-7,16]$

Bone volume calculation in three-dimensional images is a commonly used method for the evaluation of surgical results [17]. In this study, the volume and surface of the remaining mandibular bone after mandibular resection were analyzed in conventional resection simulation and tailor-made resection simulation, and the results were statistically significant (Table 3). In addition, the lower dentition was partially preserved in six of 15 patients, and in five of those, we were able to preserve aesthetic and functionally important mandibular canines. Although many studies have attempted to restore and preserve teeth through digital technologies [18-21], no attempt has been made to preserve teeth when performing segmental mandibulectomy. In this study, we proposed a method for preserving teeth even after segmental mandibulectomy. Mandibular symphysis is an important anatomical structure as well. The extrinsic tongue muscles are attached to the inner surface of the symphysis, and airway obstruction can occur if this area is resected. To prevent this event, tracheostomy becomes one of the routine procedures. In our study, there were changes in the mandibular border defect classification in 12 patients, and in six of these patients, we were able to preserve the symphysis. 
As a result, we could not only maintain their aesthetic appearance but also eliminate the risk of airway obstruction in six patients (Table 2).

The disease-specific tailor-made resection of our study was possible through preoperative surgical simulations using various diagnostic images and the fabrication of surgical guides to transfer the results of the simulation to the operating room. Since our study included a small sample and a short follow-up period, there could be controversy about the bone margin, and therefore further research is needed. Additionally, various designs of osteotomies for resection could increase the difficulty of reconstruction surgery, as well as mandibular ablation. Although this study did not deal with the accuracy of the resection and reconstruction between the simulations and the postoperative results, we hypothesized that the accuracy could be increased because of the specific shape after tailor-made mandibular resection. This hypothesis should be proven by further research.

\section{Conclusions}

In conclusion, the tailor-made mandibular resection method used disease-specific preoperative surgical simulations and surgical guides using various imaging modalities, such as CT and MRI. Within the limits of this study, tailor-made mandibular resection was a less invasive method to effectively remove mandibular lesions while preserving the important anatomical structures of the mandible.

Author Contributions: Conceptualization, J.-W.L. and J.-Y.L.; methodology, Y.-G.E., Y.L., J.J., and J.-Y.O.; software, J.-W.L.; formal analysis, B.-Y.H, Y.-G.E., and Y.L.; data curation, Y.-G.E., Y.L., J.-Y.O., and J.J.; writing-original draft. B.-Y.H., J.-Y.L., and J.-W.L.; project administration, J.-W.L.; funding acquisition, J.-W.L. All authors have read and agreed to the published version of the manuscript.

Funding: This work was supported by the National Research Foundation of Korea Grant funded by the Korean Government (NRF-2017R1D1A1B04030398).

Conflicts of Interest: The authors declare no conflicts of interest. The funders had no role in the design of the study; in the collection, analyses, or interpretation of data; and in the writing of the manuscript, or in the decision to publish the results.

\section{References}

1. Miles, B.A.; Goldstein, D.P.; Gilbert, R.W.; Gullane, P.J. Mandible reconstruction. Curr. Opin. Otolaryngol. Head Neck Surg. 2010, 18, 317-322. [CrossRef]

2. Cohen, A.; Laviv, A.; Berman, P.; Nashef, R.; Abu-Tair, J. Mandibular reconstruction using stereolithographic 3-dimensional printing modeling technology. Oral Surg. Oral Med. Oral Pathol. Oral Radiol. Endodontol. 2009, 108, 661-666. [CrossRef] [PubMed]

3. López-Arcas, J.M.; Arias, J.; Del Castillo, J.L.; Burgueño, M.; Navarro, I.; Morán, M.J.; Chamorro, M.; Martorell, V. The fibula osteomyocutaneous flap for mandible reconstruction: A 15-year experience. J. Oral Maxillofac. Surg. 2010, 68, 2377-2384. [CrossRef] [PubMed]

4. Weijs, W.L.; Coppen, C.; Schreurs, R.; Vreeken, R.D.; Verhulst, A.C.; Merkx, M.A.; Bergé, S.J.; Maal, T.J. Accuracy of virtually 3D planned resection templates in mandibular reconstruction. J. Cranio-Maxillofac. Surg. 2016, 44, 1828-1832. [CrossRef]

5. Coppen, C.; Weijs, W.; Bergé, S.J.; Maal, T.J. Oromandibular reconstruction using 3D planned triple template method. J. Oral Maxillofac. Surg. 2013, 71, e243-e247. [CrossRef] [PubMed]

6. Funayama, A.; Kojima, T.; Yoshizawa, M.; Mikami, T.; Kanemaru, S.; Niimi, K.; Oda, Y.; Kato, Y.; Kobayashi, T. A simple technique for repositioning of the mandible by a surgical guide prepared using a three-dimensional model after segmental mandibulectomy. Maxillofac. Plast. Reconstr. Surg. 2017, 39, 16. [CrossRef] [PubMed]

7. Serrano, C.; van den Brink, H.; Pineau, J.; Prognon, P.; Martelli, N. Benefits of 3D printing applications in jaw reconstruction: A systematic review and meta-analysis. J. Cranio-Maxillofac. Surg. 2019, 47, 1387-1397. [CrossRef]

8. Kwon, T.-G. Accuracy and reliability of three-dimensional computer-assisted planning for orthognathic surgery. Maxillofac. Plast. Reconstr. Surg. 2018, 40, 14. [CrossRef] 
9. Kraeima, J.; Dorgelo, B.; Gulbitti, H.; Steenbakkers, R.; Schepman, K.; Roodenburg, J.; Spijkervet, F.; Schepers, R.; Witjes, M. Multi-modality 3D mandibular resection planning in head and neck cancer using CT and MRI data fusion: A clinical series. Oral Oncol. 2018, 81, 22-28. [CrossRef]

10. El-Hafez, Y.G.A.; Chen, C.-C.; Ng, S.-H.; Lin, C.-Y.; Wang, H.-M.; Chan, S.-C.; Chen, I.-H.; Huan, S.-F.; Kang, C.-J.; Lee, L.-Y. Comparison of PET/CT and MRI for the detection of bone marrow invasion in patients with squamous cell carcinoma of the oral cavity. Oral Oncol. 2011, 47, 288-295. [CrossRef]

11. Loeffelbein, D.J.; Souvatzoglou, M.; Wankerl, V.; Martinez-Möller, A.; Dinges, J.; Schwaiger, M.; Beer, A.J. PET-MRI fusion in head-and-neck oncology: Current status and implications for hybrid PET/MRI. J. Oral Maxillofac. Surg. 2012, 70, 473-483. [CrossRef] [PubMed]

12. Mukherji, S.K.; Isaacs, D.L.; Creager, A.; Shockley, W.; Weissler, M.; Armao, D. CT detection of mandibular invasion by squamous cell carcinoma of the oral cavity. Am. J. Roentgenol. 2001, 177, 237-243. [CrossRef] [PubMed]

13. Van Cann, E.; Koole, R.; Oyen, W.; de Rooy, J.; de Wilde, P.; Slootweg, P.; Schipper, M.; Merkx, M.; Stoelinga, P. Assessment of mandibular invasion of squamous cell carcinoma by various modes of imaging: Constructing a diagnostic algorithm. Int. J. Oral Maxillofac. Surg. 2008, 37, 535-541. [CrossRef] [PubMed]

14. Nishioka, T.; Shiga, T.; Shirato, H.; Tsukamoto, E.; Tsuchiya, K.; Kato, T.; Ohmori, K.; Yamazaki, A.; Aoyama, H.; Hashimoto, S. Image fusion between 18FDG-PET and MRI/CT for radiotherapy planning of oropharyngeal and nasopharyngeal carcinomas. Int. J. Radiat. Oncol. Biol. Phys. 2002, 53, 1051-1057. [CrossRef]

15. Dai, J.; Wang, X.; Dong, Y.; Yu, H.; Yang, D.; Shen, G. Two-and Three-Dimensional Models for the Visualization of Jaw Tumors Based on CT-MRI Image Fusion. J. Craniofacial Surg. 2012, 23, 502-508. [CrossRef]

16. Lee, J.-W.; Choi, B.-J.; Lee, D.-W.; Kwon, Y.-D. Double-barrelled vascularised fibular free flap using computer-assisted preoperative planning and a surgical template for accurate reconstruction of a segmental mandibular defect. Br. J. Oral Maxillofacial Surg. 2016, 54, 102-103. [CrossRef]

17. Calvo-Guirado, J.-L.; Maté-Sánchez, J.-E.; Delgado-Ruiz, R.; Ramírez-Fernández, M.-P. Calculation of bone graft volume using 3D reconstruction system. Med. Oral. Patol. Oral. Cir. Bucal. 2011,16, e260-e264. [CrossRef]

18. Cappare, P.; Sannino, G.; Minoli, M.; Montemezzi, P.; Ferrini, F. Conventional versus digital impressions for full arch screw-retained maxillary rehabilitations: A randomized clinical trial. Int. J. Environ. Res. Public Health 2019, 16, 829. [CrossRef]

19. Cattoni, F.; Teté, G.; Calloni, A.M.; Manazza, F.; Gastaldi, G.; Capparè, P. Milled versus moulded mock-ups based on the superimposition of 3D meshes from digital oral impressions: A comparative in vitro study in the aesthetic area. BMC Oral Health 2019, 19, 230. [CrossRef]

20. Gherlone, E.; Capparé, P.; Vinci, R.; Ferrini, F.; Gastaldi, G.; Crespi, R. Conventional Versus Digital Impressions for "All-on-Four" Restorations. Int. J. Oral Maxillofac. Implant. 2016, 31, 324-330. [CrossRef]

21. Gherlone, E.F.; Ferrini, F.; Crespi, R.; Gastaldi, G.; Capparé, P. Digital impressions for fabrication of definitive "all-on-four" restorations. Implant. Dent. 2015, 24, 125-129. [CrossRef] [PubMed] 